\section{Novel stent to treat fistula and leak after gastric sleeve surgery}

Laparoscopic sleeve gastrectomy can result in complications, which include gastric fistula (5\%), and intra-abdominal locoregional collections (1\%) [1]. This report describes a novel method and stent for the treatment of a leaking gastroperitoneal fistula in a patient with a gastric sleeve.

A 23-year-old woman underwent a laparoscopic sleeve gastrectomy as treatment for morbid obesity. On Day 11 the patient complained of abdominal pain and fever. The computed tomography scan showed a fluid collection in the left upper quadrant. Because the endoscopic application of clips and fibrin glue did not resolve the leak, the patient underwent laparoscopic intervention for closure of the fistula. However, 10 days later she presented with a new episode of abdominal pain and fever. Her leukocyte count was elevated at $11700 / \mu \mathrm{L}$. An upper gastrointestinal series using iodinated contrast disclosed a left subphrenic leakage from a gastroperitoneal fistula. Esophagogastroduodenoscopy revealed a small fistulous opening ( Fig. 1 a). An upper gastrointestinal series showed the leak clear-

As the intraluminal pressure is elevated in the gastric sleeve, the sleeve was dilated using a 30-mm achalasia balloon (Rigiflex; Boston Scientific Corp., Natick, Massachusetts, USA). The Hanarostent (M.I. Tech Co., Inc., Pyeongtaek, South Korea) was then placed using the Shim's technique ( $\bullet$ Fig. 1 c,d).

This stent is almost completely covered, but it has a $10-\mathrm{mm}$ noncovered rim just below the covered upper part $\left(\begin{array}{r}\text { Fig. } 1 \text { e; }\end{array}\right.$ note that a nasojejunal feeding tube was ly ( $\bullet$ Fig. 1 b). placed to provide nutritional support, as the patient was kept nil per os). This noncovered part allows tissue ingrowth in the proximal portion, fixing the stent, preventing its migration, and sealing the lumen around the stent. The stent also has a cotton string that is pulled outside the nose and taped to the patient's cheek. This also prevents stent migration. The strings are covered by a flexible silicone tube to protect the upper airways and esophageal mucosa. After 5 days the string and silicone tube are removed. Usually, treatment with opioids is indicated, because the stent causes distension of the contracted gastric sleeve.

In the current patient, the percutaneous drain was removed 12 days later because there were no more drain secretions. After 4 weeks the stent was removed. No leaks were seen on upper gastrointestinal series ( $\bullet$ Fig. 1f). The patient was doing well 3 months later.

\section{Endoscopy_UCTN_Code_TTT_1AO_2AI}

\section{Competing interests: None}

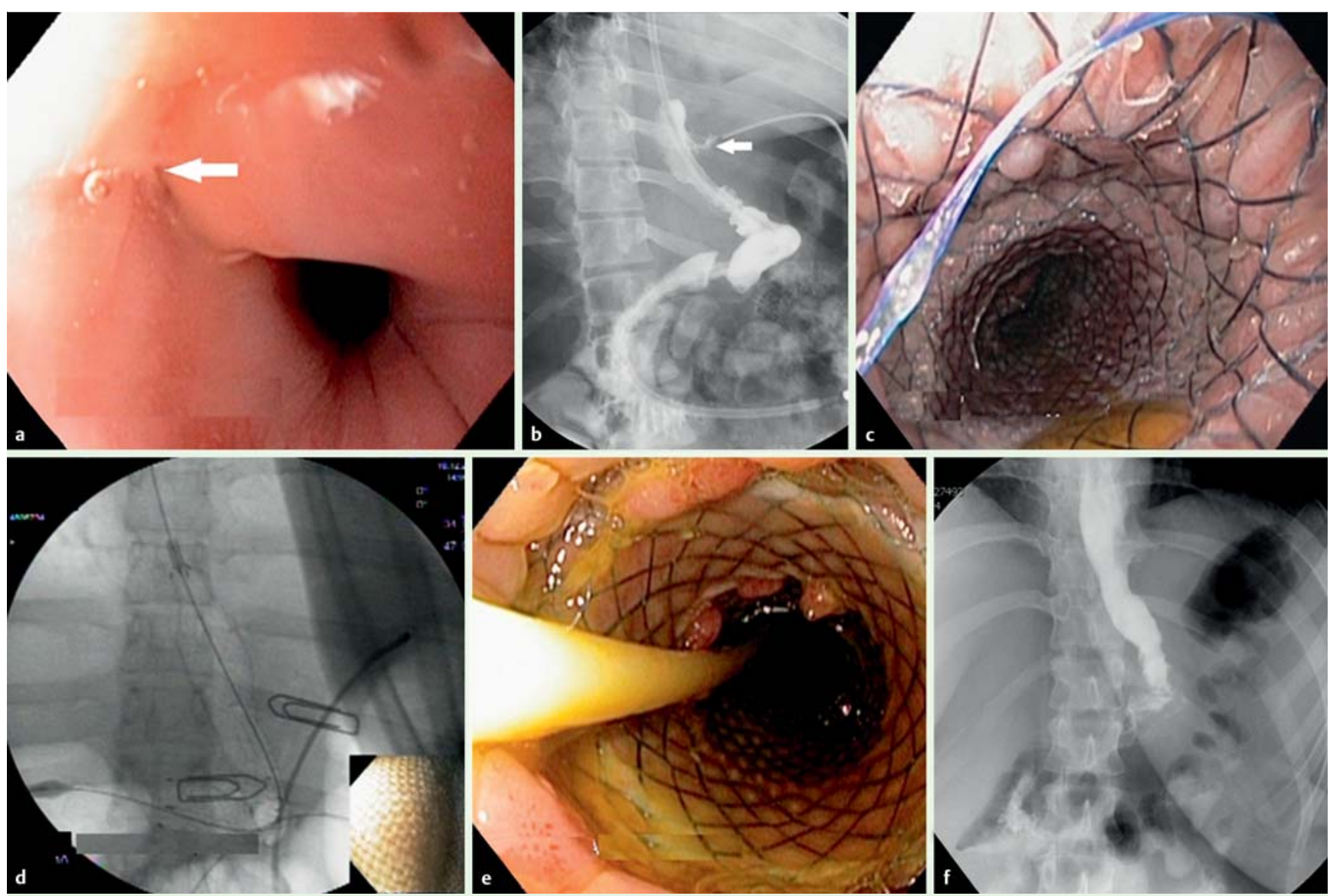

Fig. 1 Stent placement for treatment of a leaking gastroperitoneal fistula in a patient with a gastric sleeve. a The fistula orifice. $\mathbf{b}$ Radiograph showing the fistula path. c The deployed stent. $\mathbf{d}$ Radiograph during stent placement. e Hyperplastic tissue fixing the stent in place. $\mathbf{f}$ Radiograph showing the resolution of the leak. 
Marco A. D’Assuncao ${ }^{1}$, Rafael M. P. Machado ${ }^{1}$, Saverio T. N. Armellini ${ }^{1}$, Raul Cutait ${ }^{2}$, Amanda M. B. Ziegler ${ }^{2}$, Danilo Daud², Daniel Moribe ${ }^{1}$

${ }^{1}$ Department of Digestive Endoscopy Unit, Hospital Sirio Libanes, Sao Paulo, Brazil

2 Department of Surgery, Hospital Sirio Libanes, Sao Paulo, Brazil

\section{Reference}

1 Márquez MF, Ayza MF, Lozano RB et al. Gastric leak after laparoscopic sleeve gastrectomy. Obes Surg 2010; 20: 1306-1311

\section{Bibliography}

Dol http://dx.doi.org/

10.1055/s-0034-1377534

Endoscopy 2014; 46: E483-E484

(C) Georg Thieme Verlag KG

Stuttgart · New York

ISSN 0013-726X

\section{Corresponding author}

Marco Aurelio D'Assuncao, MD, MSc

Digestive Endoscopy Unit

Hospital Sirio Libanes

Rua Adma Jafet, $911^{\circ} \mathrm{SS}$

Sao Paulo

SP, 01308-050

Brazil

Fax: +55-11-31553721

mada.endoscopia@hotmail.com 